\title{
Predictive factors of central lymph node metastasis in papillary thyroid carcinoma
}

\author{
Byong Hyon Ahn, Je Ryong Kim, Ho Chul Jeong, Jin Sun Lee, Eil Sung Chang, Yong Hun Kim \\ Department of Surgery, Chungnam National University College of Medicine, Daejeon, ${ }^{1}$ Department of Surgery, Konkuk University \\ Chungju Hospital, Chungju, Korea
}

Purpose: The aim of this study was to evaluate the correlation between central lymph node (CLN) metastasis and clinicopathologic characteristics of papillary thyroid cancer (PTC). In addition, we investigated the incidence and risk factors for contralateral CLN metastasis in unilateral PTC. This study suggests the appropriate surgical extent for CLN dissection. Methods: A prospective study of 500 patients with PTC who underwent total thyroidectomy and prophylactic bilateral CLN dissection was conducted.

Results: Of 500 patients, 255 had CLN metastases. The rate of CLN metastasis was considerably higher in cases of younger patients $(<45$ years old) $(P<0.001$; odds ratio [OR], 2.357) and of a maximal tumor size greater than $1 \mathrm{~cm}(P<0.001$; OR, 3.165). Ipsilateral CLN metastasis was detected in $83.1 \%$ of cases (133/160) of unilateral PTC, only contralateral CLN metastases in $3.7 \%$ of cases (6/160), and bilateral CLN metastases in $13.1 \%$ of cases (21/160). The rate of contralateral CLN metastasis was considerably higher in cases of PTC with a large tumor size $(\geq 1 \mathrm{~cm})(P=0.019 ; 0 R, 4.440)$ and with ipsilateral CLN metastasis ( $P=0.047 ; 0 R, 2.613)$.

Conclusion: Younger age (<45 years old) and maximal tumor size greater than $1 \mathrm{~cm}$ were independent risk factors for CLN metastasis. Maximal tumor size greater than $1 \mathrm{~cm}$ and presence of ipsilateral CLN macrometastasis were independent risk factors for contralateral CLN metastasis. Therefore, both CLN dissections should be considered for unilateral PTC with a maximal tumor size greater than $1 \mathrm{~cm}$ or presence of ipsilateral CLN macrometastasis.

[Ann Surg Treat Res 2015;88(2):63-68]

Key Words: Lymph node, Metastasis, Papillary thyroid cancer

\section{INTRODUCTION}

Thyroid carcinoma accounts for approximately $1 \%$ of all tumors and one third of all head and neck tumors. Papillary thyroid carcinoma (PTC) makes up $85 \%$ to $90 \%$ of all thyroid carcinoma cases, with a reported 10-year survival rate of more than $90 \%$ [1]. Although PTC has a good prognosis, central lymph node (CLN) metastases are common. The occurrence of CLN metastasis ranges from $40 \%$ to $90 \%$ of PTC cases [2]. CLN metastasis is a well-known independent risk factor in local recurrence [3-5] but has little adverse effect on survival [5,6].
However, this conventional knowledge has become debated due to a large, recent case-based study which showed an increased mortality rate in patients with regional lymph node metastasis [1].

Prophylactic central lymph node dissection (CLND) is an accepted procedure for patients with PTC. However, CLND might increase the rates of hypoparathyroidism and vocal cord palsy, especially when bilateral CLND is performed [7]. Thus, identification of predictive factors for CLN metastasis might prevent unnecessary contralateral CLND.

Recently, PTC has been diagnosed at earlier stages through
Received June 3, 2014, Revised July 21, 2014, Accepted August 11, 2014

\section{Corresponding Author: Je Ryong Kim}

Department of Surgery, Chungnam National University Hospital, Chungnam National University College of Medicine, 282 Munhwa-ro, Jung-gu, Daejeon 301-721, Korea

Tel: +82-42-280-7175, Fax: +82-42-257-8024

E-mail: kimjr@cnu.ac.kr

\section{Copyright (c) 2015, the Korean Surgical Society}

(c) Annals of Surgical Treatment and Research is an Open Access Journal. All articles are distributed under the terms of the Creative Commons Attribution NonCommercial License (http://creativecommons.org/licenses/by-nc/3.0/) which permits unrestricted non-commercial use, distribution, and reproduction in any medium, provided the original work is properly cited. 
screening. When prophylactic CLND is performed, many CLN metastases are microscopic deposits [8].

In this study, we examine the clinicopathologic characteristics of PTC with CLN metastasis and investigate the incidence and risk factors for contralateral CLN metastasis in unilateral PTC. In addition, we describe the incidence and characteristics of CLN micrometastases and suggest the appropriate surgical extent for CLND.

\section{METHODS}

\section{Eligibility}

Our prospective study was approved by the Institutional Review Board of Chungnam National University Hospital, and written informed consent was obtained from participants. In 2001 and 2012, 500 patients with PTC who underwent a total thyroidectomy with bilateral prophylactic CLND were enrolled in this prospective nonrandomized study. Patients with clinically node-negative necks were evaluated preoperatively through neck ultrasonography, fine needle aspiration biopsy, ${ }^{18} \mathrm{~F}$ fluorodeoxyglucose $\left({ }^{18} \mathrm{~F}\right.$-FDG) PET/CT, and physical examination. All patients were clinically node negative. Being clinically nodenegative was defined as having no signs of enlarged lymph nodes (LN) during preoperative ultrasonography and no glucose uptake in LN during preoperative ${ }^{18} \mathrm{~F}$-FDG PET/CT.

\section{Surgical procedure}

All patients underwent total thyroidectomy and prophylactic bilateral CLND. First, the entirety of both lobes of the thyroid gland was removed, and then bilateral CLND was performed. CLNs are group VI LNs that surround both lobes of the thyroid and include the pretracheal, paratracheal, and prelaryngeal LNs within an area bordered laterally by the carotid sheath, at the top by the hyoid bone, at the bottom by the sternal notch, and dorsally by the prevertebral fascia. The thymus was preserved through separation from the CLNs, and the parathyroids and recurrent laryngeal nerves were also identified and preserved. Parathyroid glands that could not be preserved in situ were autotransplanted into the ipsilateral sternocleidomastoid muscle. At the end of the operation, the surgeon cut separately into the pretracheal nodes (immediately anterior to the trachea) and the paratracheal nodes (adjacent to the trachea on either side), categorized as described above, and sent them to the pathology department for examination. In unilateral thyroid cancer, ipsilateral CLNs are pretracheal and ipsilateral paratracheal LNs, while contralateral CLNs are only contralateral paratracheal LNs.

\section{Statistical analysis}

Statistical analysis was performed using SPSS ver. 12.0 (SPSS Inc., Chicago, IL, USA). Pearson chi-square or Fisher exact test for categorical variables was used in the univariate analyses of the clinical characteristics. Variables with a P-value of less than 0.05 in the univariate analysis were included in multivariate logistic regression analysis.

\section{RESULTS}

The clinicopathologic characteristics are presented in Table 1. Of the 500 patients, 255 had metastatic CLNs. Univariate analysis suggested that younger age ( $<45$ years old), male sex, a large tumor size $(\geq 1 \mathrm{~cm})$, bilateral multiple nodules, and the presence of capsular invasion or extrathyroidal extension were significant factors in CLN metastasis (Table 1). With CLNs removed in the multivariate analysis, the rate of CLN metastasis was considerably higher in the cases of younger patients $(<45$ years old) $(\mathrm{P}<0.001$; odds ratio [OR], 2.357) and large tumor size $(\geq 1 \mathrm{~cm})(\mathrm{P}<0.001 ; \mathrm{OR}, 3.165)$ (Table 2).

Table 1. Correlation between clinicopathological characteristics and central lymph node metastasis in papillary thyroid cancer

\begin{tabular}{|c|c|c|c|}
\hline Characteristic & $\begin{array}{l}\text { No. of patients } \\
\quad(n=500)\end{array}$ & Positive CLN & P-value \\
\hline Age (yr) & & & 0.001 \\
\hline$<45$ & 160 & $109(68)$ & \\
\hline$\geq 45$ & 340 & $146(43)$ & \\
\hline Sex & & & 0.038 \\
\hline Male & 58 & 37 (64) & \\
\hline Female & 442 & $218(49)$ & \\
\hline Tumor size (cm) & & & 0.004 \\
\hline$\leq 0.5$ & 149 & $39(26)$ & \\
\hline$>0.5,<1$ & 197 & $93(47)$ & \\
\hline$\geq 1$ & 154 & $123(80)$ & \\
\hline Bilaterality & & & 0.008 \\
\hline Unilateral & 341 & $160(47)$ & \\
\hline Bilateral & 159 & $90(57)$ & \\
\hline Multiplicity & & & 0.005 \\
\hline Solitary & 288 & $130(45)$ & \\
\hline Multiple & 212 & $125(59)$ & \\
\hline Capsule invasion & & & 0.004 \\
\hline Yes & 314 & $192(61)$ & \\
\hline No & 186 & $63(34)$ & \\
\hline Extrathyroidal extension & & & 0.002 \\
\hline Yes & 248 & $153(62)$ & \\
\hline No & 252 & $102(40)$ & \\
\hline Lymphovascular invasion & & & 0.005 \\
\hline Yes & 401 & $243(61)$ & \\
\hline No & 99 & $12(12)$ & \\
\hline No. of CLN removed & $9.05 \pm 7.03$ & $10.21 \pm 6.25$ & 0.580 \\
\hline No. of CLN metastasis & - & $1.52 \pm 2.76$ & \\
\hline
\end{tabular}

Values are presented as number (\%) or mean \pm standard deviation. CLN, central lymph node.

a) Pearson chi-square test for categorical variables was used for univariate analyses of the clinical characteristics. 
The trend of CLN metastasis in unilateral PTC patients is depicted in Fig. 1. Of 341 patients with unilateral PTC, 160 had CLN metastases. We excluded isthmic PTC in patients with unilateral PTC analysis.

Ipsilateral CLN metastasis was detected in $83.1 \%$ of cases $(133 / 160)$ of CLN metastases in patients with unilateral PTC, only contralateral CLN metastases in $3.7 \%(6 / 160)$, and bilateral CLN metastases in $13.1 \%$ (21/160). The clinicopathologic characteristics of patients with contralateral CLN metastases are shown in Table 3. In the univariate analysis, large tumor size $(\geq 1 \mathrm{~cm})$, lymphovascular invasion, and positive ipsilateral CLNs were significant predictors of contralateral CLN metastases in unilateral PTC $(\mathrm{P}<0.05)$ (Table 3). In the multivariate analysis, the rate of contralateral CLN metastasis was considerably higher in the cases of PTC with a large tumor size $(\geq 1 \mathrm{~cm})(\mathrm{P}=0.019$; $\mathrm{OR}, 4.440)$ or ipsilateral CLN metastasis ( $\mathrm{P}=0.047$; OR, 2.613) (Table 4).

Permanent hypocalcemia occurred in 22 patients (4.4\%), while permanent recurrent laryngeal nerve paralysis did not occur in the present study (Table 5).

Table 2. Correlation between clinicopathologic characteristics and central lymph node metastasis in papillary thyroid cancer by multivariate logistic regression analysis

\begin{tabular}{lccc}
\hline \multicolumn{1}{c}{ Variable } & $\beta \pm \mathrm{SE}$ & P-value & Odds ratio $(95 \% \mathrm{Cl})$ \\
\hline Age $<45 \mathrm{yr}$ & $0.857 \pm 0.235$ & $<0.001$ & $2.357(1.488-3.735)$ \\
Male gender & $0.496 \pm 0.337$ & 0.153 & $1.612(0.837-3.104)$ \\
Tumor size $\geq 1 \mathrm{~cm}$ & $1.801 \pm 0.303$ & $<0.001$ & $3.165(1.697-7.299)$ \\
Bilateral tumor & $0.463 \pm 0.362$ & 0.957 & $1.013(0.781-3.229)$ \\
Capsular invasion & $0.538 \pm 0.343$ & 0.116 & $1.712(0.875-3.352)$ \\
Lymphovascular invasion & $0.847 \pm 0.368$ & 0.086 & $1.312(0.373-2.699)$ \\
Constant & $-1.003 \pm 0.451$ & - & - \\
\hline
\end{tabular}

$\mathrm{SE}$, standard error; $\mathrm{Cl}$, confidence interval.

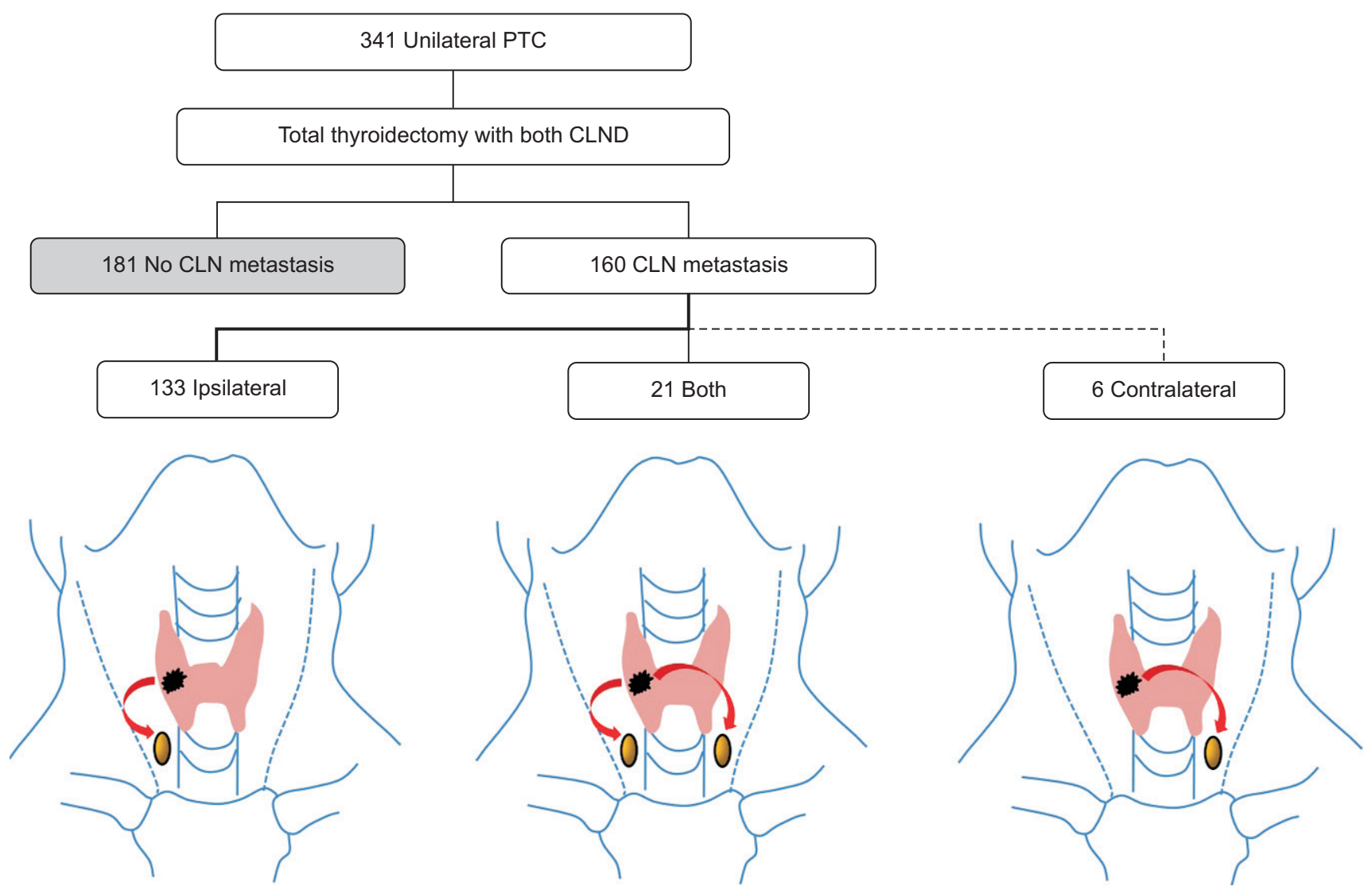

Fig. 1. Trend of central lymph node (CLN) metastasis in unilateral papillary thyroid cancer (PTC). CLND, central lymph node dissection. 
Table 3. Correlation between clinicopathological characteristics and contralateral central lymph node metastasis in unilateral papillary thyroid cancer

\begin{tabular}{|c|c|c|}
\hline Variable & $\begin{array}{c}\text { Contralateral } \\
\text { CLN metastasis }(n=27)\end{array}$ & P-value \\
\hline Age (yr) & & 0.086 \\
\hline$<45$ & $12 / 102$ & \\
\hline$\geq 45$ & $15 / 239$ & \\
\hline Sex & & 0.067 \\
\hline Male & $6 / 39$ & \\
\hline Female & $21 / 302$ & \\
\hline Tumor size $(\mathrm{cm})$ & & $<0.001$ \\
\hline$\leq 0.5$ & $5 / 122$ & \\
\hline$>0.5,<1$ & 9/133 & \\
\hline$\geq 1 \mathrm{~cm}$ & $13 / 86$ & \\
\hline Multiplicity & & 0.447 \\
\hline Solitary & $22 / 279$ & \\
\hline Multiple & $5 / 62$ & \\
\hline Capsule invasion & & 0.377 \\
\hline Yes & $17 / 187$ & \\
\hline No & $10 / 154$ & \\
\hline Extrathyroidal extension & & 0.495 \\
\hline Yes & $13 / 143$ & \\
\hline No & $14 / 198$ & \\
\hline Lymphovascular invasion & & 0.003 \\
\hline Yes & $27 / 262$ & \\
\hline No & $0 / 79$ & \\
\hline Ipsilateral central LN (+) & & $<0.001$ \\
\hline Yes & $21 / 154$ & \\
\hline No & 6/187 & \\
\hline
\end{tabular}

CLN, central lymph node; LN, lymph node.

${ }^{\text {a) }}$ Pearson chi-square test or Fisher exact test for categorical variables was used for univariate analyses.

Table 4. Correlation between clinicopathologic characteristics and contralateral central lymph node metastasis in unilateral papillary thyroid cancer by multivariate logistic regression analysis

\begin{tabular}{lccc}
\hline \multicolumn{1}{c}{ Variable } & $\beta \pm$ SE & P-value & $\begin{array}{c}\text { Odds ratio } \\
(95 \% \mathrm{Cl})\end{array}$ \\
\hline Tumor size $\geq 1 \mathrm{~cm}$ & $1.491 \pm 0.637$ & 0.019 & $\begin{array}{c}4.440 \\
(1.273-15.486)\end{array}$ \\
$\begin{array}{l}\text { Lymphovascular } \\
\text { invasion }\end{array}$ & $1.719 \pm 0.000$ & 0.066 & 1.312 \\
$\begin{array}{l}\text { Ipsilateral LN (+) } \\
\text { Constant }\end{array}$ & $0.960 \pm 0.505$ & 0.047 & 2.613 \\
\hline
\end{tabular}

$\mathrm{SE}$, standard error; $\mathrm{Cl}$, confidence interval.

Eighty-nine patients had CLN micrometastases (Table 6). The rate of CLN micrometastases was higher in cases with a maximal tumor size of less than $1 \mathrm{~cm}(\mathrm{P}=0.002)$. All the CLN micrometastases occurred on the ipsilateral side of the tumor.
Table 5. Complications $(n=400)$

\begin{tabular}{cc}
\hline Complication & No. $(\%)$ \\
\hline Hypocalcemia & \\
Transient & $212(42.4)$ \\
Permanent & $22(4.4)$ \\
Hoarseness & $31(6.2)$ \\
Transient & $0(0)$ \\
Permanent & $3(0.6)$ \\
Chylous fistula & \\
\hline
\end{tabular}

Table 6. Characteristics of subgroups of nodal involvement in papillay thyroid carcinoma

\begin{tabular}{|c|c|c|c|}
\hline Variable & $\begin{array}{c}\text { Microscopic } \\
\text { metastases } \\
(\mathrm{n}=89)\end{array}$ & $\begin{array}{c}\text { Macroscopic } \\
\text { metastases } \\
(\mathrm{n}=166)\end{array}$ & P-value ${ }^{a)}$ \\
\hline Age (yr) & & & 0.109 \\
\hline$<45$ & $32(36)$ & $77(46)$ & \\
\hline$\geq 45$ & $57(64)$ & $89(54)$ & \\
\hline Sex & & & 0.475 \\
\hline Male & $11(12)$ & $26(16)$ & \\
\hline Female & $78(88)$ & $140(84)$ & \\
\hline Maximal tumor size $(\mathrm{cm})$ & & & 0.002 \\
\hline$\leq 0.5$ & $20(23)$ & $19(11)$ & \\
\hline$>0.5,<1$ & $39(44)$ & $55(33)$ & \\
\hline$\geq 1$ & $30(33)$ & $92(56)$ & \\
\hline Bilaterality & & & 0.302 \\
\hline Unilateral & $61(69)$ & $103(62)$ & \\
\hline Bilateral & $28(31)$ & $63(38)$ & \\
\hline Multiplicity & & & 0.797 \\
\hline Solitary & $46(52)$ & $83(50)$ & \\
\hline Multiple & $43(48)$ & $83(50)$ & \\
\hline Capsule invasion & & & 0.470 \\
\hline Yes & $65(73)$ & $128(77)$ & \\
\hline No & $24(27)$ & $38(23)$ & \\
\hline Extrathyroidal extension & & & 0.070 \\
\hline Yes & $47(53)$ & $107(64)$ & \\
\hline No & $42(47)$ & $59(36)$ & \\
\hline Lymphovascular invasion & & & 0.342 \\
\hline Yes & $83(93)$ & $159(96)$ & \\
\hline No & $6(7)$ & $7(4)$ & \\
\hline Contralateral central $\mathrm{LN}(+)$ & & & $<0.001$ \\
\hline Yes & $0(0)$ & $27(17)$ & \\
\hline No & $89(100)$ & $139(83)$ & \\
\hline
\end{tabular}

Values are presented as number (\%).

LN, lymph node.

${ }^{a)}$ Pearson chi-square test for categorical variables was used for univariate analyses of the clinical characteristics.

\section{DISCUSSION}

PTC responds relatively well to surgery and has a good prognosis. However, PTC might recur if the first operation is conducted improperly. A standard treatment for PTC has 
not been established. A growing number of studies present prophylactic CLND in synchronization, and some authors even consider CLNs as important as the primary tumor [9]. Therapeutic CLND should be performed on patients with PTC who have preoperative clinical LN metastasis, despite the controversy over clinical NO (cNO) PTC patients $[7,10,11]$. Most studies agree that CLNs are involved most frequently in PTC with LN metastasis. The LNs in the central group are most commonly involved in metastases, so there might be a significant risk of recurrence in the central group [12,13]. In addition, reoperation is relatively difficult and complicated in patients who develop loco-regional recurrence in the central group $[14,15]$. Several studies suggest that prophylactic CLND should not be performed routinely for the majority of cNO PTC patients, even though a greater incidence of subclinical LN metastasis is expected [16]. Performing CLND has significant associated morbidities, such as recurrent laryngeal nerve injury and hypoparathyroidism. Therefore, it is important to determine the surgical extent of prophylactic CLND in the initial operation for patients with PTC. Recent studies on CLND report transient vocal cord palsy in 3\% to $6 \%$ of cases and permanent hypoparathyroidism in $3 \%$ to $4 \%$ of cases [17-21]. In this study, half the patients developed temporary hypoparathyroidism, and $4 \%$ continued to experience symptoms for more than 6 months after surgery. These results are similar to those in previous research [7,22]. Permanent recurrent laryngeal nerve paralysis did not occur in the present study. Careful preoperative nodal evaluation for metastasis should be done in order to avoid unnecessary CLND for pNO patients. However, CLNs are usually small and difficult to identify with ultrasound. Recent studies have shown that the sensitivity in identifying CLN metastases using ultrasonography is $40 \%$ to $60 \%[23,24]$.

Various predictive factors and staging systems have been used to determine PTC prognosis. Age, gender, tumor size, lymphovascular invasion, extrathyroidal extension, and LN metastasis are generally accepted factors in survival and local recurrence. LN metastases are an independent risk factor for loco-regional recurrence and distant metastasis [25]. Evidence from large population-based studies shows that patients with regional LN metastases have poor prognosis and higher mortality $[1,17]$. Numerous studies have found CLN metastases in $50 \%$ to $70 \%$ of PTC patients $[13,20,26,27]$. In the present study, $51 \%$ of PTC patients (255/500) had CLN metastases. Most studies agree that ipsilateral CLN metastases are frequently involved in the LN metastasis of PTC $[8,13,28]$. Prophylactic CLND ipsilateral to the tumor associated with

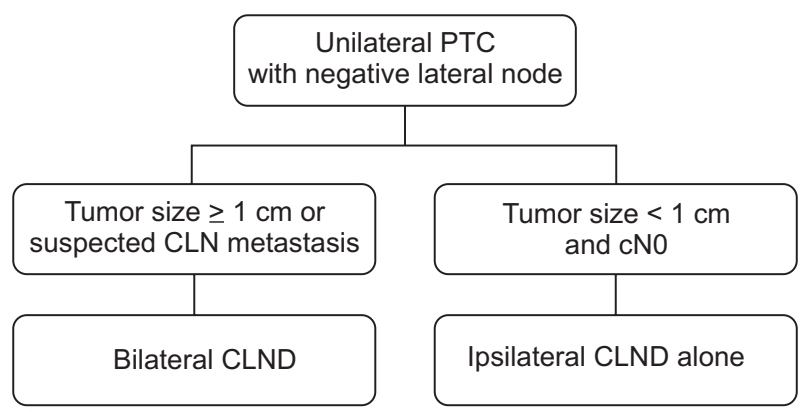

Fig. 2. Suggested scheme of decision making in unilateral papillary thyroid cancer (PTC). The ipsilateral central lymph node (CLN) metastasis could be evaluated by clinical examination or intraoperative pathology. CLND, CLN dissection.

total thyroidectomy could be an effective strategy for reducing the rates of permanent hypoparathyroidism and hoarseness. Generally, for unilateral PTC, the rate of metastasis to contralateral CLN was very low, and the rate of disease-free survival did not improve after bilateral CLND, indicating that contralateral CLND is unnecessary [12,29]. Among the unilateral PTC patients with CLN metastases participating in the present study, contralateral CLN metastasis occurred mostly in the patients who had ipsilateral CLN macrometastasis or a maximal tumor size greater than $1 \mathrm{~cm}$ (Tables 4, 6).

We recommend that total thyroidectomy with simultaneous completion of contralateral CLND be performed in the presence of ipsilateral CLN macrometastasis in intraoperative frozensection pathology. This approach could limit unnecessary contralateral CLND for node-negative patients based on intraoperative pathological findings. According to the results of this study, both prophylactic CLND should be considered for unilateral PTC with a large tumor size $(\geq 1 \mathrm{~cm})$ or the presence of ipsilateral CLN macrometastasis. In contrast, prophylactic ipsilateral CLND has a satisfactory surgical extent for the initial operation in patients with PTC who have a small tumor and no ipsilateral CLN macrometastasis (Fig. 2).

There were no local recurrences during the follow-up period for this study. Local recurrence and disease-free survival could not be described because of the short follow-up duration. A long-term follow-up of the present study is necessary to evaluate local recurrence and disease-free survival.

\section{CONFLICTS OF INTEREST}

No potential conflict of interest relevant to this article was reported. 


\section{REFERENCES}

1. Lundgren CI, Hall P, Dickman PW, Zedenius J. Clinically significant prognostic factors for differentiated thyroid carcinoma: a population-based, nested casecontrol study. Cancer 2006;106:524-31.

2. Moo TA, McGill J, Allendorf J, Lee J, Fahey $\mathrm{T}$ 3rd, Zarnegar R. Impact of prophylactic central neck lymph node dissection on early recurrence in papillary thyroid carcinoma. World J Surg 2010;34:1187-91.

3. Shah JP, Loree TR, Dharker D, Strong EW, Begg C, Vlamis V. Prognostic factors in differentiated carcinoma of the thyroid gland. Am J Surg 1992;164:658-61.

4. Scheumann GF, Gimm O, Wegener G, Hundeshagen H, Dralle H. Prognostic significance and surgical management of locoregional lymph node metastases in papillary thyroid cancer. World J Surg 1994:18:559-67.

5. Mazzaferri EL, Jhiang SM. Long-term impact of initial surgical and medical therapy on papillary and follicular thyroid cancer. Am J Med 1994:97:418-28.

6. Rossi RL, Cady B, Silverman ML, Wool MS, Horner TA. Current results of conservative surgery for differentiated thyroid carcinoma. World J Surg 1986;10:612-22.

7. Lee YS, Kim SW, Kim SW, Kim SK, Kang HS, Lee ES, et al. Extent of routine central lymph node dissection with small papillary thyroid carcinoma. World J Surg 2007;31:1954-9.

8. Qubain SW, Nakano S, Baba M, Takao S, Aikou T. Distribution of lymph node micrometastasis in pNO well-differentiated thyroid carcinoma. Surgery 2002; 131:249-56.

9. Lee J, Song Y, Soh EY. Central lymph node metastasis is an important prognostic factor in patients with papillary thyroid microcarcinoma. J Korean Med Sci 2014:29:48-52.

10. Sugitani I, Fujimoto Y. Symptomatic versus asymptomatic papillary thyroid microcarcinoma: a retrospective analysis of surgical outcome and prognostic factors. Endocr J 1999;46:209-16.
11. Sakorafas GH, Giotakis J, Stafyla V. Papillary thyroid microcarcinoma: a surgical perspective. Cancer Treat Rev 2005;31:42338.

12. Ito $\mathrm{Y}$, Jikuzono T, Higashiyama T, Asahi S, Tomoda C, Takamura Y, et al. Clinical significance of lymph node metastasis of thyroid papillary carcinoma located in one lobe. World J Surg 2006;30:1821-8.

13. Gimm O, Rath FW, Dralle H. Pattern of lymph node metastases in papillary thyroid carcinoma. Br J Surg 1998;85:252-4.

14. Moley JF, Lairmore TC, Doherty GM, Brunt LM, DeBenedetti MK. Preservation of the recurrent laryngeal nerves in thyroid and parathyroid reoperations. Surgery 1999;126:673-7.

15. Kim MK, Mandel SH, Baloch Z, Livolsi VA, Langer JE, Didonato L, et al. Morbidity following central compartment reoperation for recurrent or persistent thyroid cancer. Arch Otolaryngol Head Neck Surg 2004;130:1214-6.

16. Hay ID, Hutchinson ME, Gonzalez-Losada T, McIver B, Reinalda ME, Grant CS, et al. Papillary thyroid microcarcinoma: a study of 900 cases observed in a 60-year period. Surgery 2008;144:980-7.

17. Tisell LE, Nilsson B, Molne J, Hansson G, Fjalling M, Jansson S, et al. Improved survival of patients with papillary thyroid cancer after surgical microdissection. World J Surg 1996;20:854-9.

18. Sywak M, Cornford L, Roach P, Stalberg P, Sidhu S, Delbridge L. Routine ipsilateral level VI lymphadenectomy reduces postoperative thyroglobulin levels in papillary thyroid cancer. Surgery 2006;140:1000-5.

19. Henry JF, Gramatica L, Denizot A, Kvachenyuk A, Puccini M, Defechereux T. Morbidity of prophylactic lymph node dissection in the central neck area in patients with papillary thyroid carcinoma. Langenbecks Arch Surg 1998;383:167-9.

20. Goropoulos A, Karamoshos K, Christodoulou A, Ntitsias T, Paulou K, Samaras A, et al. Value of the cervical compartments in the surgical treatment of papillary thyroid carcinoma. World J Surg 2004:28: 1275-81.

21. Gemsenjager E, Perren A, Seifert B, Schuler G, Schweizer I, Heitz PU. Lymph node surgery in papillary thyroid carcinoma. J Am Coll Surg 2003;197:182-90.

22. Shindo M, Wu JC, Park EE, Tanzella F. The importance of central compartment elective lymph node excision in the staging and treatment of papillary thyroid cancer. Arch Otolaryngol Head Neck Surg 2006;132:650-4.

23. Vergez S, Sarini J, Percodani J, Serrano E, Caron P. Lymph node management in clinically node-negative patients with papillary thyroid carcinoma. Eur J Surg Oncol 2010;36:777-82.

24. Choi YJ, Yun JS, Kook SH, Jung EC, Park YL. Clinical and imaging assessment of cervical lymph node metastasis in papillary thyroid carcinomas. World J Surg 2010;34:1494-9.

25. Pellegriti G, Scollo C, Lumera G, Regalbuto C, Vigneri R, Belfiore A. Clinical behavior and outcome of papillary thyroid cancers smaller than $1.5 \mathrm{~cm}$ in diameter: study of 299 cases. J Clin Endocrinol Metab 2004; 89:3713-20.

26. Pereira JA, Jimeno J, Miquel J, Iglesias $M$, Munne A, Sancho JJ, et al. Nodal yield, morbidity, and recurrence after central neck dissection for papillary thyroid carcinoma. Surgery 2005;138:1095-100.

27. Mirallié E, Visset J, Sagan C, Hamy A, Le Bodic MF, Paineau J. Localization of cervical node metastasis of papillary thyroid carcinoma. World J Surg 1999;23:970-3.

28. Machens A, Hinze R, Thomusch O, Dralle $\mathrm{H}$. Pattern of nodal metastasis for primary and reoperative thyroid cancer. World J Surg 2002;26:22-8.

29. Wada N, Duh QY, Sugino K, Iwasaki H, Kameyama K, Mimura T, et al. Lymph node metastasis from 259 papillary thyroid microcarcinomas: frequency, pattern of occurrence and recurrence, and optimal strategy for neck dissection. Ann Surg 2003:237:399-407. 